\title{
ADOLESCENTES GESTANTES: UM OLHAR PARA OS SENTIMENTOS GERADOS NESTA VIVÊNCIA
}

\author{
Bianca Paes, Jorge Luís Ferreira Abrão \\ Universidade Estadual Paulista - FCL/UNESP. Curso de Psicologia, Assis - SP. E-mail: bi_paes@hotmail.com \\ Financiamento: FAPESP. $\mathrm{n}$ ㅇ CAAE: 17580813.0.0000.5401
}

\begin{abstract}
RESUMO
A adolescência é uma fase marcada pela transição entre a infância e a idade adulta, caracterizando-se por alterações tanto nos aspectos físicos e mentais, como também sociais. Entretanto, acontecimentos como por exemplo a gravidez na adolescência, podem levar o adolescente a tomar consciência de forma prematura das responsabilidades inerentes à vida adulta. Diante disso, a pesquisa tem por objetivo compreender, a partir de um enfoque psicanalítico, a vivência de adolescentes durante a gestação, discriminando as possíveis expectativas e angústias. Para cumprir os objetivos da pesquisa, propõe-se um estudo qualitativo por intermédio da realização de entrevistas semi-dirigidas, com três mães que apresentam idades que variam de 14 a 17 anos, que estavam em atendimento no Hospital Regional de Assis - SP. Após a realização das entrevistas, os dados obtidos foram analisados e interpretados para uma reflexão e possível compreensão das experiências emocionais destas gestantes durante a adolescência.
\end{abstract}

Palavras chaves: Psicanálise; Adolescência; Maternagem; Gestação; Hospital.

\section{PREGNANT ADOLESCENTS: A LOOK AT THE FEELINGS ARISING FROM SUCH EXPERIENCE}

\begin{abstract}
Adolescence is a period marked by the transition between childhood and adult age, characterized by changes in both the physical and mental aspects, as well as social aspects. However, events such as teenage pregnancy, may lead adolescents to be prematurely aware of the responsibilities inherent in adulthood. Before addition, the research aims to understand, from a psychoanalytic view, the experience of adolescents during the pregnancy, detailing the possible expectations and anxieties. To accomplish the research objectives, it is proposed a qualitative study through the realization of semi-directed interviews, with three mothers who are between 14 and 17 years-old, and were in care at the Hospital Regional de Assis - SP. After the interviews, the data were analyzed and interpreted to a further reflection and possible comprehension of the emotional experiences of those pregnant during the adolescence.
\end{abstract}

Keywords: Psychoanalysis; Adolescence; Motherhood; Gestation; Hospital. 


\section{INTRODUÇÃO}

Na atualidade há uma tendência a valorizar a adolescência enquanto um período privilegiado da vida, de tal forma que esta etapa de desenvolvimento tem sofrido grande ampliação, fazendo com que os anos da vida dedicados à adolescência se tornem cada vez mais longos. Não é incomum vermos crianças que se denominam pré-adolescentes e adultos que buscam preservar características adolescentes constituindo o que se convencionou denominar de "adultescência".

Segundo Kernie e Cupa (2012) a adolescência implica desconstruir o infantil, permitindo assim, que o sujeito vá se estruturando em novos paradigmas, num movimento onde vai ao encontro de si próprio, ou seja, tornando-se sujeito de sua própria história dentro de um corpo agora sexuado. A adolescência é uma questão de mudanças: no início, de transformações somáticas; posteriormente, de mudanças caracterizadas pela atividade fantasiástica e, enfim, pelas modificações que intervêm no conjunto da vida psíquica.

Apesar dessa valorização, Levisky em seu livro "Adolescência: reflexões Psicanalíticas" de 1998, considera que a adolescência será sempre um período de crises e desequilíbrio. Esses sentimentos são por conta das mudanças fisiológicas que se realizam quanto às repercussões psicológicas de inserção do jovem na comunidade adulta, ou seja, o processo de evolução do adolescente faz com que ele reviva situações passadas, as quais serão vividas com maior ou menor dificuldade. E isso dependerá das suas experiências infantis, das relações afetivas primárias, do modo de resolução das relações triangulares por conta do conflito edipiano, de suas angústias e temores.

No livro "Adolescer - Estudos Revisados sobre Adolescência" de 2003 de Outeiral, ele considera que o jovem no decorrer do seu desenvolvimento vai abandonando as fantasias realizadas e buscando uma adequação à realidade (posição consciente consigo e com o mundo). 0 autor também propõe que uma das tarefas essências da adolescência é a estruturação da identidade, sendo que é nesse período que ela se define, tornando essa experiência como um dos elementos principais do processo adolescente.

Entretanto, se por um lado a adolescência tem sido amplamente valorizada, de tal forma que este período possa ser desejado e cultivado como uma etapa privilegiada da vida, por outro lado alguns acontecimentos podem levar o adolescente a tomar consciência de forma prematura das responsabilidades inerentes à vida adulta, como por exemplo, a gravidez.

A gravidez na adolescência, sobretudo nos primeiros anos desta fase, entre 14 a 17 anos, é um acontecimento, na grande maioria das vezes, inesperado que impõe às adolescentes 
responsabilidades e mudanças de vida em um período bastante conturbado, em decorrência de todas as transformações e vivências emocionais pelas quais elas estão passando. Temos aqui um conflito entre as obrigações impostas pela gravidez, que farão aflorar responsabilidades da vida adulta e os desejos da adolescência tão valorizada na contemporaneidade.

Quando se fala de adolescência é importante considerar que essa fase é marcada por crises, mudanças, readaptação ao novo corpo e às novas atitudes frente à vida. Associando esses fatores a uma gravidez, espera-se que tal episódio possa ser um evento difícil na vida da adolescente, o que poderá levá-la a precisar de ajuda para superar tais dificuldades.

Com isso, a presente pesquisa tem como objetivos: compreender a vivência das adolescentes durante a gestação, discriminando as expectativas e as angústias em relação a esse acontecimento; reconhecer a realidade da população alvo e seu ambiente familiar e social, bem como o apoio ou não de seus familiares; analisar se há algum tipo de preparo para esse momento, seja ele familiar ou individual e discriminar fatores que possam favorecer ou prejudicar o reconhecimento da gravidez (apoio familiar, independência financeira, renuncia de projetos futuros).

\section{METODOLOGIA}

Depois da pesquisa ter sido aprovada pelo Comitê de Ética em Pesquisa, esta foi realizada no município de Assis - SP e as três adolescentes gestantes, população alvo da pesquisa, foram encontradas na Unidade Materno Infantil do Hospital Regional de Assis, pois esta é referência para o atendimento de gestantes de risco em idade de 10 a 15 anos. Vale ressaltar que o número do protocolo de aprovação do comitê de ética é 17580813000005401.

Para cumprir o objetivo da pesquisa foram realizadas entrevistas semi-estrutrurada com o roteiro pré-definido, mas de sequência flexível com as três gestantes participantes, que apresentavam 14, 15 e 17 anos. A entrevista abordou perguntas que facilitaram a compreensão do entrevistador em relação às experiências vivenciadas pelas adolescentes durante a gestação, exemplo delas:

1) Como é sua rotina de vida?

2) Em que momento descobriu que estava grávida?

3) Como sua família recebeu a notícia? E o pai da criança?

4) Foi um impacto para você a notícia? Qual é o maior desafio e a maior dificuldade enfrentada por você?

5) Quais são suas expectativas em relação ao futuro? 
6) Que tipo de mudança de vida que a gravidez trouxe?

7) Como você imagina a relação com o seu bebê quando ele nascer?

Ressalta-se que este trabalho é estudo clínico qualitativo de natureza psicanalítica com gestantes primíparas.

\section{RESULTADOS}

A partir das entrevistas realizadas com as adolescentes gestantes, foram encontradas algumas categorias de análise, que traduzem o significado de alguns conflitos vivenciados por elas, quais sejam: 1) A gravidez como algo difícil de ser aceito; 2) Reações dos pais/responsáveis diante da gravidez na adolescência; 3) Reação do pai da criança que está para nascer; 4) Impacto social causado pela gestação da adolescência; 5) Prevenção e conhecimento de métodos contraceptivos.

Tendo como primeira categoria de análise a questão da gravidez como algo difícil de ser aceito, a partir dos relatos das adolescentes percebe-se que o emocional delas está abalado e a gravidez é vivida como um momento de renúncias. Nota-se que a gestação é vista por elas como a perda de identidade, a interrupção dos estudos e um corte em seu desenvolvimento, impossibilitando-a de fazer coisas que fazia antes. A insatisfação da adolescente em relação ao enfrentamento da gravidez também é algo presente, não sendo vista primeiramente como algo prazeroso, mas como algo que traz o medo, a insegurança e a angústia. A título de exemplo, temse a seguir, uma fala da adolescente J. de 17 anos:

“Depois a gente acostuma né? Se Deus mandou, agora eu tenho que cuidar né? Eu não queria, mas já que ele mandou".

Em relação à segunda categoria (reação dos pais/responsáveis), percebe-se que uma gestação na adolescência é um processo social que afeta significativamente as relações familiares, definindo novas identidades sociais. Diante disso, foi possível de observar nos discursos das adolescentes o medo, a preocupação, a insegurança e a angústia quando tiveram que contar para seus pais/responsáveis sobre o ocorrido.

Poucas são as famílias que aceitam a situação da gestação na adolescência e procuram lidar com compreensão e afeto com as jovens. No entanto, quando os pais/responsáveis eram comunicados sobre o ocorrido, a primeira reação que tinham era a de ficar sem conversar com elas. Mas, depois de elaborada a situação, o vínculo conseguia ser reestabelecido. Segue à baixo, o relato da adolescente T. de 16 anos exemplificando a situação: 
“Ah , meu pai né (maior desafio), ele não gostou não, tinha parado de falar comigo. Não queria que eu fosse na casa dele. Agora eu falo (com ele), agora é normal”

A terceira categoria é a reação dos pais da criança que está para nascer. Apenas uma das adolescentes relatou que o pai da criança é presente, as outras duas disseram que não estão mais com os pais. Sendo que essa condição não era esperada por elas, preferindo estar ainda junto com os parceiros.

Outra categoria de análise é o impacto social que a gestação na adolescência pode trazer nas vidas dessas jovens. Pode-se levar em consideração como conflito a ser resolvido os estudos das adolescentes, já que todas elas são estudantes. Por conta da gravidez, tiveram que pedir licença escolar (6 meses); dessa forma, realizam as atividades em casa e vão para a escola em data de prova. Dessa forma, não há um abandono completo dos estudos, acreditando que este ainda seja importante e necessário para a formação. Nenhuma delas trabalha, algo que corresponde a dependência financeira, seja por parte dos responsáveis ( 2 adolescentes), seja por parte do parceiro (1 adolescente). Além disso, as três disseram que pretendem voltar a estudar, assim que pararem de amamentar, momento no qual a criança ficará ou com a mãe ou com a irmã mais nova.

Apesar das adolescentes relatarem que continuarão estudando, para Diniz (2010) as mulheres que engravidam na adolescência tendem a ter menos anos de estudos que as outras, indicando que, um estado de baixa escolaridade pode propiciar uma repetição precoce da gravidez, sendo que a maternidade cria dificuldades para retomar os estudos. Em relação a opinião de Pinto \& Rodrigues (1999) uma consequência social da gravidez é a restrição das possibilidades de futuras melhorias nas condições socioeconômicas das adolescentes. Frequentemente as adolescentes grávidas se veem obrigadas a abandonar a escola e o emprego.

Como última categoria de análise tem-se a prevenção. Percebe-se com os relatos, que duas adolescentes disseram que não usavam preservativos e não tomavam anticoncepcionais, mesmo sabendo da existência deles. Apenas uma adolescente disse que tomava a injeção mensalmente para se prevenir, e que também usava preservativo, mas que deixou de usar por descuido. Notase, portanto, uma relação entre a esfera cognitiva e afetiva no tocante a sexualidade na adolescência.

\section{DISCUSSÃO}

A partir disso, percebeu-se que os conflitos vivenciados pelas adolescentes com a descoberta da gravidez se davam na percepção dessa gestação como um acontecimento 
indesejado no primeiro momento, nas reações dos pais/responsáveis com a descoberta da gravidez na adolescência e na reação do próprio pai da criança que está para nascer. A adolescente vive este momento como algo repleto de medo, insegurança e angústias, somado à aquisição de uma nova identidade para a qual pode não estar totalmente preparada, além da cobrança social que o papel maternal representa.

Como angústias das adolescentes, ressalta-se todos os sentimentos de imaturidade em relação a essa vivência, como por exemplo, as inseguranças, as preocupações e os medos excessivos, o desafio de contar o ocorrido para a família, e até mesmo o maior desafio, a aceitação da gravidez, já que é algo que não se espera como objetivo de vida nessa idade.

Já como expectativas coloca-se em pauta a ansiedade pela chegada do filho, a imaginação em relação às características físicas do bebê, a questão do cuidado e também do carinho.

Torna-se necessário também reconhecer a realidade da população alvo e seu ambiente familiar, o qual se mostra mais compreensivo e continente, após um tempo em que a notícia foi recebida. Entretanto, todas as jovens são financeiramente dependentes, nenhuma trabalhava, só estudava, tendo também como consequência da gravidez não planejada a interrupção dos estudos. Dessa forma, diante das três entrevistas, percebe-se que as adolescentes puderam contar com o apoio familiar, o qual serviu de amparo, sendo capaz de sustentar uma gravidez na adolescência.

\section{CONCLUSÃO}

Diante das entrevistas, foi possível de se observar que as adolescentes vivem este momento como algo repleto de insegurança, somado à aquisição de uma nova identidade para a qual pode não estar totalmente preparada. A partir desses fatores torna-se necessário uma reflexão para que se compreenda os motivos que levam as meninas a engravidar, já que esse acontecimento pode ser considerado como multicausal. A gravidez nessa faixa etária não pode ser vista como um fato isolado, mas como parte da busca da identidade da jovem e de uma certa atitude de rebeldia diante da família e do contexto histórico-social amplo do qual faz parte. Vale também levar em consideração, que muitas meninas engravidam porque desejam, pois acreditam que é isso que o namorado quer, desejam a liberdade da casa dos pais, querem ser vistas como adultas, ou por outros motivos.

A prevenção de gravidez indesejada na adolescência requer uma educação formal bem delineada, que permita o recebimento de informações adequadas sobre educação sexual e 
métodos contraceptivos, além de solicitar um canal comunicacional aberto para que a adolescente possa expor suas ideias, temores e dúvidas.

Diante desses fatores, a construção de um programa para adolescentes que trate de temas como sexualidade, gravidez, prevenção de doenças sexualmente transmissíveis e AIDS deve considerar os aspectos sociais, culturais e econômicos da comunidade em que são desenvolvidos, para que a partir disso, os profissionais de saúde procurem estabelecer um relacionamento de confiança com essas adolescentes, a fim de prevenir o desejo da adolescente de provocar um aborto. A jovem deve receber apoio psicológico nesse momento, além de orientações sobre métodos contraceptivos, pré-natal e apoio da família, companheiro e sociedade. Além disso, é preciso ouvir e valorizar os sentimentos e preocupações dos jovens para conhecer o mundo adolescente: as pressões e os constrangimentos podem dar pistas para as dificuldades que enfrentam na hora de optar e usar um método anticoncepcional, e dos entraves para a negociação dos métodos entre parceiros.

A partir do descrito, um dos propósitos desse trabalho é também sugerir aos profissionais que trabalham com essa população alvo, palestras dirigidas aos adolescentes, utilizando recursos didáticos que os sensibilizem para o uso de métodos contraceptivos e, desenvolver um trabalho a partir das necessidades apontadas pelos jovens para que sejam atores ativos nesse processo, 0 que contribuirá na sua formação para a vida e o mundo. Com isso, o conhecimento dos fatores relacionados à gravidez na adolescência dentro de cada realidade social pode se constituir em um importante caminho para a implementação de medidas que possam modificar esse quadro e favorecer o exercício saudável da sexualidade desses adolescentes.

\section{REFERÊNCIAS}

CARVALHO, Geraldo; BARROS, Sonia. Fatores psicossocias relacionados à gravidez na adolescência. 1. ed. São Paulo: Acta Paul Ent, 2000. v.13. p. 9-17.

DINIZ, Nataly. Gravidez na adolescência um desafio social. Minas Gerais, 2010.

KERNIER, Nathalie, \& CUPA, Dominique. Adolescência: muda psíquica à procura de continentes. Ágora: Estudos em Teoria Psicanalítica, 2012. 15(spe). P 453-467.Recuperado em 11 de dezembro de 2013, de SciELO.

LEVISKY, David. Adolescência: reflexões psicanalíticas. São Paulo: Casa do Psicólogo, 1998.

OUTEIRAL, José. Adolescer - Estudos Revisados sobre Adolescência. Rio de Janeiro, 2003.

PINTO, Ana Lucia. \& RODRIGUES, Flórida. A gravidez na adolescência. Rio de Janeiro: Centro Nacional Bertha Lutz de Assistência,Educação e Promoção da Mulher e da Família, 1986. 